\title{
Definition of Planned and Unplanned Transfer of Public Transport Service and User Decisions to Use Routes with Transfers
}

\author{
Subeh Chowdhury, Avishai (Avi) Ceder \\ University of Auckland, New Zealand
}

\begin{abstract}
In the literature, there is a lack of clarity on attributes that classify a planned transfer as being a connection designed by policy makers and public transport network planners. This calls for a proper guideline to be developed to support policy makers and planners in designing "seamless" transfers. The present study has two main objectives. The first is to determine the attributes that define a connection as being planned transfer. The second is to understand the difference in transit users' perceptions between planned and unplanned transfers and, thus, their decision to use routes with transfers. The proposed definition of planned transfer consist of five attributes: network integration, integrated timed-transfer, integrated physical connection of transfers, information integration, and fare and ticketing integration. A survey was conducted at two major public transport terminals in Auckland, New Zealand. Results support the attributes identified for the definition. Findings suggest that transit users' willingness to use transfer routes increases when attributes of the connections are more closely aligned to being planned. The study provides a guide-
\end{abstract}


line for policy makers and public transport network planners to serve as a basis for planning new and improving existing connections to be planned transfers.

\section{Introduction}

Heightened awareness for the need to promote public transport (PT) as a viable alternative to cars has resulted in a global trend towards planned and integrated land use and transport development (Ibrahim 2003; Matas 2004; Ulengin et al. 2007). Many authorities are investing in new infrastructure to improve the quality of PT services (Vassallo et al. 2012). An example is the Auckland Transport Regional Public Transport Plan (Auckland Transport 2010), which is a statutory document created for the purpose of developing an integrated PT network to provide Aucklanders with a sustainable transport system in a safe, integrated, responsive, and affordable manner. One of the key components by which Auckland Transport (AT) plans to achieve full integration of the network is through facilitation of intermodal and intramodal transfers. Studies (Guo and Wilson 2004; Ceder et al. 2009) have shown that commuters are only willing to tolerate the inconvenience caused by transfers if the perceived benefits of selecting a route with transfers are greater than the direct route. A number of studies (Liu et al. 1997; Vande Walle and Steenberghen 2006; Bamberg et al. 2007; Beirao and Sarsfield-Cabral 2007; Guo and Wilson 2007; Iseki and Taylor 2009; Currie and Loader 2010; Guo and Wilson 2011; Sharaby and Shiftan 2012) have been conducted to identify the operational and psychological factors that dictate the inconvenience felt by transit users when undertaking routes with transfers. These studies have indicated the importance of including transfers in the planning stage of an integrated transport system. Yet, despite the awareness, in general, there is no tradition in service planning to treat transfers as a distinct topic (Guo and Wilson 2011).

In the literature, there remains a lack of clarity in attributes that define a connection as being a planned transfer. Which attributes of a transfer constitute the connection as being designed by policy makers? Clearly specifying the definition of a planned transfer will provide policy makers and PT network planners with a better guide in designing "seamless" transfers for an integrated multimodal PT network. The present study contributes to existing knowledge on policy and travel behavior by (1) identifying the attributes that define a transfer as being planned and (2) determining the difference in transit users' perception of planned and unplanned transfers and, thus, their decision to use transfer routes. A guideline is developed to serve as a basis for planning new and improving existing connections to be planned transfers. 
The paper is organized as follows: Section 2 is a literature review; Section 3 provides the proposed definition of planned transfers; Section 4 is a description of the survey design; Section 5 presents results; Section 6 is a discussion of the results; Section 7 is the guideline for policy makers and PT network planners; and Section 8 is the conclusion.

\section{Literature Review}

\section{Purpose of an Integrated Public Transport Network}

The aim of an integrated multimodal transport system is to provide transit users with a "wide spectrum" of destination choices and also with convenient, accessible, comfortable, safe, speedy, and affordable transport system while supporting future demand (Ibrahim 2003; Luk and Olszewski 2003; Ulengin et al. 2007). With an integrated transport system, transit users do not board a single line, but a whole system (Clever 1997). One of the key components in achieving an user-friendly integrated transport system is to develop "seamless" transfers (Luk and Olszewski 2003). Easy transfers provide transit users with access into the entire public transport network, thus making transfers a benefit rather than something to be avoided (Maxwell 2003). Hutchinson (2009) discusses that for urban journeys, commuters are willing to use transfer routes given integration among operators. Integration reduces the cost of transfers for users, which increases the attractiveness of PT (Hidalgo 2009).

\section{Location for Transfers}

The main purpose of transfer centers is to facilitate links among PT services. In Madrid, Spain, construction of transfer centers has been used as an important measure for development of multimodal integration to promote PT use (Vassallo et al. 2012). Some literature (Clever 1997; Vassallo et al. 2012) has illustrated the importance of strategic location of transfer centers to reduce the exchange time for travelers transferring from one transport mode to the next. A study by Currie and Willis (1998) suggested that physical integration of terminals is a key factor in facilitating transfers between terminals. The study noted that although some of the surveyed stations and bus stops were in close proximity to each other, transfers among these stations could not be classified as being "planned" since the stops were separate from the station area. Physical integration of terminals needs to be designed from a planning and management level (Currie and Willis 1998). Well-designed and appropriate location of transfer centers were shown to benefit the surrounding community by creating opportunity for development (Volinski and Page 2006). Involvement of the community during the design phase instigates 
the transfer center to be perceived as a symbol of pride for the community. Security provisions at the center provide a safe environment for the surrounding area (Volinski and Page 2006).

\section{Trip Attributes Influencing Perception of Transfer Routes}

The trip attributes that have been identified to be most significant in the transit user decision making process to select routes with transfers are travel time, travel cost, transfer waiting and walking time, transfer information, fare ticketing system, security, and comfort at terminal (Atkins 1990; Callaghan and Vincent 2007; Iseki and Taylor 2009; Molin and Chorus 2009; Muller and Furth 2009; Sharaby and Shif$\tan$ 2012). Several studies have identified personal safety, travel time, and transfer time as the most sensitive indicators for transit user perception of transfer routes (Vande Walle and Steenberghen 2006; Zhou et al. 2007; Muller and Furth 2009; Eboli and Mazzulla 2012; Hadas and Ranjitkar 2012).

Personal safety at terminals has been revealed to be the most important factor in transit user decisions to use PT (Atkins 1990; Zhou et al. 2007; Kumar et al. 2011; Eboli and Mazzulla 2012). Travel time, for commuters, has been found to be more significant than transfer waiting and walking time (Vande Walle and Steenberghen 2006; Xumei et al. 2011). There is much support for transfer waiting time being valued more highly than transfer walking time (Vande Walle and Steenberghen 2006; Iseki and Taylor 2009). A well-integrated fare system has been shown to have a positive impact on ridership of PT by improving transit user intentions to use routes with transfers (Buehler 2011; Sharaby and Shiftan 2012). Other studies have shown that integrated information systems are required to increase the perceived ease of making a transfer (Bachok 2007; Grotenhuis et al. 2007; Molin and Chorus 2009). A high-quality information system is an essential factor in increasing ridership by retaining existing riders and attracting potential users (Eboli and Mazzulla 2012). Comfort at the transfer terminal has also been identified to be a determining factor in transit users' perceived ease of making a transfer (Guo and Wilson 2011). Eboli and Mazzulla (2012) discusses that although comfort has been identified as an important factor in service satisfaction, it is less important in the transit user decision process than other service factors.

\section{Research Need}

Despite the well-understood importance of transfers in an integrated multimodal transport system, there is a lack of clarity in the attributes that define a planned transfer. Without a clear definition, policy makers and PT network planners will be unable to adequately design transfers for an integrated PT network. For example, 
the objectives outlined in the Auckland Transport Regional Public Transport Plan (Auckland Transport 2010) aim to enable "seamless" transfers through network branding, an integrated network of services, high frequency services provided by the Quality Transit Network (QTN) and Rapid Transit Network (RTN), good access to quality service information, an integrated fare and ticketing system, and a welldesigned PT infrastructure (Auckland Transport 2010). The document states the following:

Transport interchange facilities at RTN stations and major nodes on the QTN will facilitate passenger transfer by reducing transfer distance and time, providing a safe environment for waiting and passenger movement and giving access to transport information and trip planning help.

It is clear that although a certain amount of planning has been undertaken to facilitate transfers, complete comprehension of the level of planning required to produce "seamless" transfers is lacking. The outcome of this study is aimed to provide policy makers and PT network planners with a more in-depth understanding of the level of planning required to create a successful integrated multimodal PT network through facilitation of transfers and the affect this has on ridership of transfer routes.

\section{Definition of Planned and Unplanned Transfer}

A "planned" transfer is a connection that has been intentionally designed by policy makers and PT network planners in the planning stage of the multimodal PT network to improve service efficiency and convenience to transit users (Ceder 2007). An "unplanned" transfer is defined as a connection that has been created by transit users from available PT services without any additional guidance on how to make the connection. In this study, the following five attributes are proposed with justifications to define transfers in a PT network to be considered as being "planned."

\section{Network Integration}

Routes are required to be connected from a network perspective to allow transit users to access a wider range of destinations. Planning connections, as such, will facilitate transfer to be perceived as a benefit rather than something to be avoided (Clever 1997). Proper integration of a multimodal transport system will reduce wasteful duplication of route services and, thus, improve the utilization of resources (Ibrahim 2003). 


\section{Integrated Timed-Transfer}

The aim of integrated timed-transfers is to interconnect the multimodal PT network such that the transfer times are minimized (Clever 1997; Maxwell 1999). This is achieved by operators synchronizing their scheduled routes to develop a pulsedhub network (Becker and Spielberg 1999). Since the performance of timed-transfer is dependent on schedule reliability, implementation improves the overall reliability of the transport system (Maxwell 2003). Routes and scheduling are required to be designed simultaneously (Becker and Spielberg 1999).

\section{Integrated Physical Connection for Transfers}

Terminals are required to be physically connected for the transfers among them to be considered as being "planned" (Currie and Willis 1998). Integration between terminals has been defined as sheltered walkways between terminals, security measures at connected walkways, and information provisions such as signage providing guidance between the connected terminals, a map of the local street area, and the locations of connected walkways (Currie and Willis 1998; Ibrahim 2003; Luk and Olszewski 2003).

\section{Information Integration}

Transfers are perceived as being barriers to using PT, and, therefore, suitable information is required to make connections easy and convenient (Grotenhuis et al. 2007). An integrated information system is essential to facilitate urban and interurban multimodal trip planning (Zografos et al. 2008). With many advanced PT information systems available, real-time information can be made accessible directly to the transit user en route (Zhang et al. 2011). Such an information system can assist transit users with pre-planning transfers and then providing guidance en route, thereby reducing the chances of missed connections and providing travel support (Grotenhuis et al. 2007; Zhang et al. 2011).

\section{Fare and Ticketing Integration}

A common global approach in the development of an integrated multimodal transport system has been fare and ticketing system integration (Luk and Olszewski 2003; Matas 2004; Garcia and Azan 2005; Hidalgo 2009). Fare system integration of a multimodal PT network has been shown to facilitate "seamless" transfers and thus encourage the use of transfer routes (Sharaby and Shiftan 2012). A simple user-friendly integration, such as smart cards, can improve the efficiency of boarding and egressing (Luk and Olszewski 2003; Blythe 2004). 
A summary of the main characteristics of each planned transfer attribute is provided in Table 1. It should be noted that the table does not provide an exhaustive list but, rather, a direction to the level of planning required at an early stage by policy makers and PT planners.

\section{Table 1. Main Characteristics of Planned Transfer Attributes- Survey of Planned and Unplanned Public-Transport Transfers}

\begin{tabular}{|l|l|}
\hline Planned Transfer & Characteristics \\
\hline Network integration & $\begin{array}{l}\text { - Physical overlap of service lines } \\
\text { - Combination of high frequency routes and low frequency routes } \\
\text { (feeder services) } \\
\text { - Network coverage } \\
\text { - Easy accessibility to PT network }\end{array}$ \\
\hline $\begin{array}{l}\text { Integrated timed- } \\
\text { transfer }\end{array}$ & $\begin{array}{l}\text { - Minimizef transfer waiting time } \\
\text { - Synchronizef scheduled routes }\end{array}$ \\
\hline $\begin{array}{l}\text { Integrated physical } \\
\text { connection for transfers }\end{array}$ & $\begin{array}{l}\text { - Sheltered walkways } \\
\text { - Security measures to protect transit users between seperate } \\
\text { stations/stops } \\
\text { Information such as directional signage and maps to link stations/ } \\
\text { stops at seperate locations }\end{array}$ \\
\hline Information integration & $\begin{array}{l}\text { - Journey planner to assist transit users in planning their transfers } \\
\text { among all PT services }\end{array}$ \\
- Real-time information (arrival/departure/delay times) at stations/ \\
$\begin{array}{l}\text { stops } \\
\text { En-route guidance providing real-time information } \\
\text { - Maps and timetables for all PT services at stations/stops }\end{array}$
\end{tabular}

\section{User Preference Survey}

To confirm the proposed definition and determine transit user perceptions of planned and unplanned transfers, a user preference survey was undertaken in Auckland, New Zealand. This section provides a description of the survey locations selected and the questionnaire designed.

\section{Survey Locations}

The Northern Busway and Britomart were chosen as survey locations. Local feeder routes are connected to five designated stations along the Northern Expressway 
(Ceder et al. 2009). Transfers occur between local routes and the main line (Ceder et al. 2009). A majority of the buses entering and leaving the Auckland CBD begin and end their trip at Britomart. The hub provides a link between the main bus, train, and ferry services of the Auckland region (Auckland Transport 2012); this allows transit users with an opportunity to make transfers at Britomart. A comparison of the facilities available at both survey locations to assist transit users in making transfers was conducted. The comparison suggested that transfers at the Northern Busway can be classified as being "planned" more closely than transfers taking place at Britomart.

\section{Questionnaire and Implementation}

The questionnaire was composed of questioins related to general socio-demographics, trip characteristics, and a hypothetical scenario. The band width for the socio-demographic questions, age and income, was adopted from the NZ census questionnaire (Statistics New Zealand 2012). To participants who were currently using a transfer route, questions on details of the transfer connection and usage satisfaction were asked. To participants who were not using a transfer route, a multi-choice question was asked on improvements to trip attributes that would increase their willingness to do so.

All participants were asked a question on whether they would choose an alternative hypothetical transfer route when comparing the route to a hypothetical direct route with travel time of 40 minutes. The hypothetical transfer route scenarios had travel time savings of 10,15 , and 20 minutes with varying types of connection. This question was designed to determine transit user perceptions of planned and unplanned transfers.

The survey was conducted for 10 weekdays ( 5 days for each location) during commuter morning peak period (7-10 AM).

\section{Survey Results}

\section{Participant Socio-Demographic and Trip Characteristics}

A total of 131 transit users from the Northern Busway participated, of whom 55 percent were from the upper suburbs of North Shore and 45 percent were from the lower suburbs. From Britomart, a total of 125 transit users participated in the survey. Of the 125 participants, 50 percent were from the central suburbs, 14 percent were from the east, 13 percent were from the west, 11 percent were from the north, and the remaining 11 percent were from the southern suburbs. Table 2 provides a summary of the participants' socio-demographic and trip characteristics. The 
main differences between the two samples are (1) the proportion of frequent riders (80\%) was greater in Northern Busway; (2) 55 percent of the participants from Northern Busway were in the age group of 24 to 44, and 50 percent from Britomart were less than 24; (3) a greater proportion of Northern Busway participants were in the high income ranges, and (4) the number of transit users making transfers was shown to be higher (36\%) at Northern Busway.

Table 2. Socio-Demographics and Trip Characteristics

\begin{tabular}{|c|c|c|}
\hline Socio-Demographic & Britomart (125) & Northern Busway (131) \\
\hline \multicolumn{3}{|c|}{ Gender } \\
\hline Female & $58(46 \%)$ & $82(63 \%)$ \\
\hline Male & $67(54 \%)$ & $49(37 \%)$ \\
\hline \multicolumn{3}{|c|}{ Age } \\
\hline$<24$ & $62(50 \%)$ & $22(17 \%)$ \\
\hline $24-44$ & $45(36 \%)$ & $72(55 \%)$ \\
\hline $45-64$ & $17(14 \%)$ & $29(22 \%)$ \\
\hline$>65$ & 0 & $8(6 \%)$ \\
\hline \multicolumn{3}{|c|}{ Income } \\
\hline$<\$ 30,000$ & $58(47 \%)$ & $26(20 \%)$ \\
\hline$\$ 30,001-\$ 70,000$ & $63(51 \%)$ & $87(66 \%)$ \\
\hline$\$ 70,001-\$ 100,000$ & $3(2 \%)$ & $16(12 \%)$ \\
\hline$>\$ 100,001$ & 0 & $1(0.8 \%)$ \\
\hline \multicolumn{3}{|c|}{ Trip Characteristics } \\
\hline Frequent rider & $84(67 \%)$ & $105(80 \%)$ \\
\hline Non-frequent rider & $41(33 \%)$ & $26(20 \%)$ \\
\hline Transfer users & $28(23 \%)$ & $47(36 \%)$ \\
\hline
\end{tabular}

\section{Trip Attributes of Transfer Routes}

As discussed previously, both Britomart and Northern Busway offer transit users provisions to facilitate ease of making transfers. Participants who currently used transfer routes were asked about their satisfaction. A 5-point Likert scale (very poor/very good) was used as the response measure. Rating scales such as the Likert Scale are designed to measure one specific perception of the statement presented to the respondent (May 2011). Rating scales have been commonly used in travel 
behavior studies (Heath and Gifford 2002; Bamberg et al. 2007; Gatersleben and Uzzell 2007; Carrus et al. 2008).

Of the participants from Northern Busway, 61 percent rated their transfer route to be 4 (Good). Of the participants from Britomart, 54 percent rated their transfer route to be 3 (neutral), and none rated their routes to be greater than 3 . The average transfer waiting time and walking time for users of the Northern Busway was found to be 12 minutes and 8 minutes, respectively.

Similarly, for Britomart, the average transfer waiting and walking time was found to be 6 minutes and 5 minutes, respectively. To determine transit users' perceived ease of using the transfer routes, participants were asked which provisions are available to assist them in making the transfer. Figure 1 illustrates that a higher proportion of transit users from Northern Busway perceived more provisions to be available to them than users of Britomart.

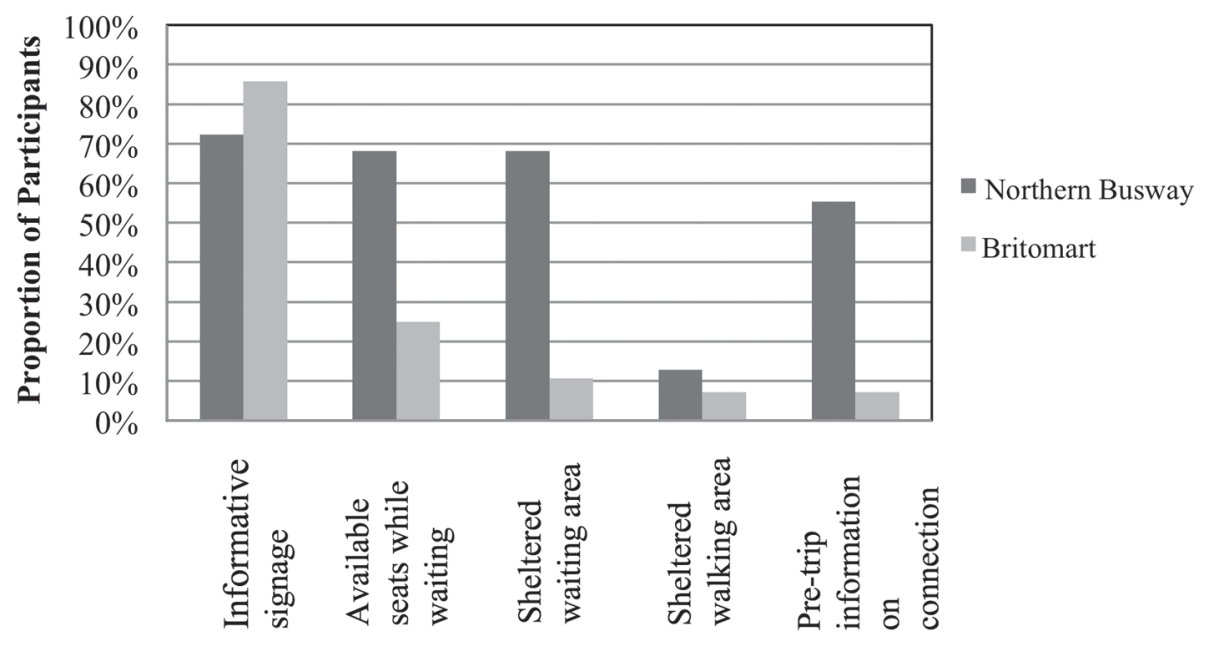

Figure 1. Proportion of transfer route users perceiving that facilities are offered by operator

Participants who currently do not use transfer routes were asked about which improvements to trip attributes would increase their willingness to do so. Figure 2 shows the proportion of transit users willing to use transfer routes given improvements made to trip attributes. 
Users of Britomart were willing to use transfer routes given more connected routes, more information on transfers, and the total transfer time being less than 20 minutes. Network integration was shown to have the most influence on willingness.

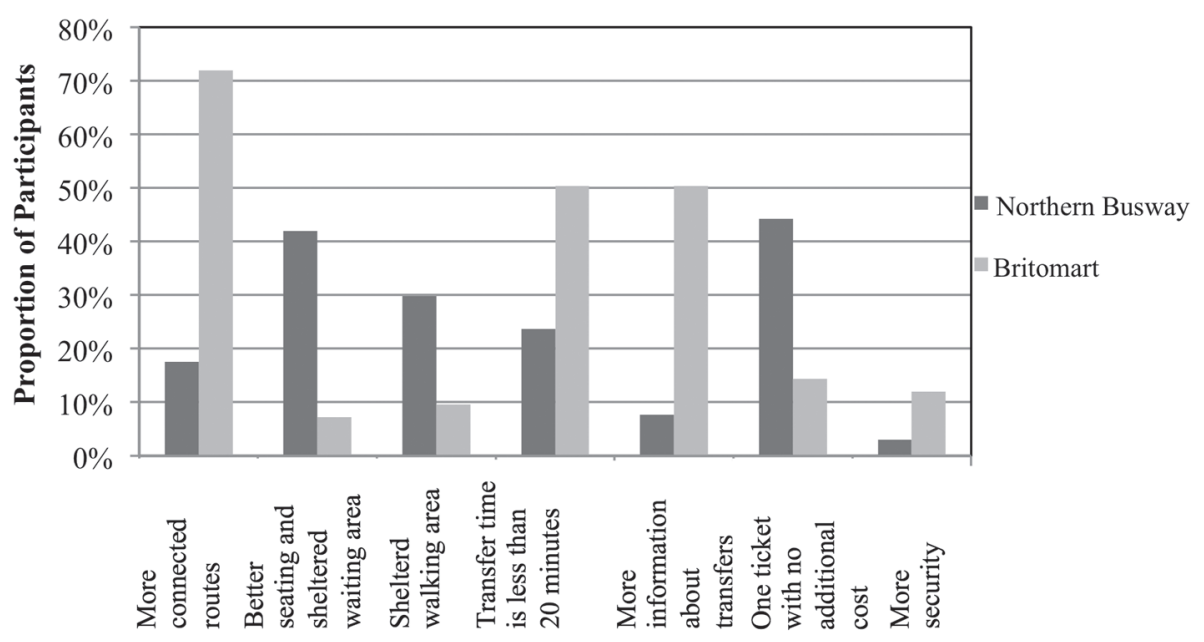

Figure 2. Proportion of transit users willing to use transfer routes given improvements to trip attributes

Northern Busway users' willingness depended on better seating areas, sheltered walking areas, and an integrated ticketing system that offers no additional cost for transfers. Cost of transfer was shown to have a greater influence than the trip attributes related to comfort.

\section{Hypothetical Transfer Route Scenarios}

As discussed earlier, participants were given hypothetical transfer route scenarios to determine transit user willingness to use the routes given varying level of provisions for the connection and travel time savings. To determine the statistical difference in the responses for each scenario, the data were fit into generalized linear models (GLM) of the Poisson family. The statistical package, $R$, was used to fit the data. Poisson distribution was chosen, as the response measures are in counts (Graybill 1976). The p-value of the responses for each option was used to assess statistical differences between Option 1 (reference) and Options 2, 3, and 4.

Table 3 shows the proportion of transit users willing to use the transfer route present in each option and the respective $p$-value. For models of this form, model fit is not an issue. The predicted values from the model line up exactly with the observed data. 
Table 3. Transit User Preference for Hypothetical Transfer Routes

\begin{tabular}{|c|c|c|c|c|}
\hline Savings (mins) & Option 1 & Option 2 & Option 3 & Option 4 \\
\hline \multicolumn{5}{|c|}{ Britomart } \\
\hline 10 & $80 \%$ (reference) & $55 \%(0.021)$ & $17 \%(0.000)$ & $7 \%(0.000)$ \\
\hline 15 & $73 \%$ (reference) & $58 \%(0.115)$ & $6 \%(0.000)$ & $2 \%(0.000)$ \\
\hline 20 & $77 \%$ (reference) & $43 \%(0.000)$ & $43 \%(0.000)$ & $7 \%(0.000)$ \\
\hline \multicolumn{5}{|c|}{ Northern Busway } \\
\hline 10 & $75 \%$ (reference) & $63 \%(0.234)$ & $12 \%(0.000)$ & $11 \%(0.000)$ \\
\hline 15 & $79 \%$ (reference) & $68 \%(0.278)$ & $30 \%(0.000)$ & $26 \%(0.000)$ \\
\hline 20 & $90 \%$ (reference) & $85 \%(0.644)$ & $34 \%(0.000)$ & $30 \%(0.000)$ \\
\hline
\end{tabular}

\section{Discussion of Survey Results}

Findings from analysis of the survey data support the definition of planned transfers developed in the present study. A comparison of the perceived provisions offered at the two stations to facilitate transfers has shown that transit users perceived more provisions to be available to them when the connections are more closely aligned to being planned. Although the same provisions are provided at both stations, on average, more than 50 percent of the transit users who used transfer routes at Northern Busway (planned) perceived the facilities to be related to their connection and, on average, only 30 percent of transit users did from Britomart (unplanned).

For transit users who currently did not make transfers, their willingness to use transfer routes was influenced most by improvements to operational trip attributes. The intention of transit users from the Northern Busway was influenced most by improvements to the fare and ticketing system. An integrated ticketing system was one of the criteria that the connections of Northern Busway scored "partially achieved" for being planned. Analysis of responses for all hypothetical transfer route scenarios revealed strong statistical evidence ( $p$-value $<0.001$ ) of significant difference between the proportion of transit users willing to use the routes for Option 1 and the routes for Options 3 and 4. Such findings suggest the importance of an integrated physical connection of transfers to transit user perceptions of transfer routes. For the 10-minute travel-time-savings scenario, statistical evidence was shown to exist for the difference in the proportion of transit users from Britomart who were willing to use routes for Option 1 and Option 2. 
This result demonstrates the importance of information integration to transit user perceptions of transfer routes.

It was noted that a higher proportion of transit users from the Northern Busway was willing to use the transfer routes for Options 3 and 4 in the 15-minute and 20-minute travel-time-savings scenarios. A possible reason for this is due to the journey times for participants from the Northern Busway ranging from 30 to 90 minutes. The journey times for the northern, southern, western, and eastern routes to Britomart ranged from 40 to 90 minutes and was 10 to 20 minutes for routes from the central suburbs to Britomart. As mentioned previously, 50 percent of the participants from Britomart were from the central suburbs; thus, the 15- and 20-minute travel-time-saving scenarios were not applicable to the majority.

\section{Possible Guidelines for Planned Transfers}

The objective of the guidelines is to assist decision makers and PT network planners in improving existing and developing new transfer routes to provide transit users with "seamless" transfers in a multimodal PT network. As discussed previously, the five main attributes of a planned transfer are network integration, integrated timed-transfer, integrated physical connection of transfers, information integration, and fare and ticketing integration. These five attributes can be grouped into two stages of planning: (1) initial and (2) operation. Network integration and integrated physical connection of transfers need to be achieved during the initial planning stage of the multimodal PT network, as the two attributes involve possible infrastructure construction. Integrated timed-transfer, information integration, and fare and ticketing integration can be achieved during the operation planning stage.

\section{Guideline A: New Transfer Routes}

In the development of new transfer routes, decision makers should aim to achieve all five attributes of a planned transfer. Route generation should be created from two points of view: user and operator. For users, the route should be designed to minimize transfer time and maximize the comfort and convenience of the connection. For operators, the route should minimize the cost of operation and maximize revenue (ridership) of transfer routes (Verma and Dhingra 2005). Use of this guideline is demonstrated with an example by providing recommendations for Auckland Transport Regional Public Transport Plan, as shown in Table 4. 


\section{Table 4. Recommendations for Auckland Transport Regional Public Transport Plan}

\begin{tabular}{|l|l|l|}
\hline $\begin{array}{l}\text { Planned } \\
\text { Transfer } \\
\text { Elements }\end{array}$ & $\begin{array}{l}\text { Achieved/ } \\
\text { Partially } \\
\text { Achieved }\end{array}$ & \\
\hline $\begin{array}{l}\text { Network } \\
\text { integration }\end{array}$ & Achieved & - \\
\hline $\begin{array}{l}\text { Fare } \\
\text { integration }\end{array}$ & Achieved & - \\
\hline $\begin{array}{l}\text { Integrated } \\
\text { timed- } \\
\text { transfer }\end{array}$ & $\begin{array}{l}\text { Partially } \\
\text { achieved }\end{array}$ & $\begin{array}{l}\text { The plan (Auckland Transport 2010), on page 21 under Policy 2.1, } \\
\text { states that connection between services will be timed to minimize } \\
\text { transfer waiting times. This is planned to be achieve by provid- } \\
\text { ing frequent and reliable services (Objective 1 and 4 on page 14). } \\
\text { Increasing the frequency of services will improve reliability and } \\
\text { reduce transfer waiting times, but it will not minimize transfer } \\
\text { waiting times. Therefore, it is recommended that to achieve "seam- } \\
\text { less" transfers in Auckland's multimodal PT network, PT operators } \\
\text { must focus on methods of synchronizing their scheduled routes to } \\
\text { minimize transfer waiting times. }\end{array}$ \\
\hline $\begin{array}{l}\text { Integrated } \\
\text { physical } \\
\text { connection } \\
\text { for transfers }\end{array}$ & $\begin{array}{l}\text { Partially } \\
\text { achieved }\end{array}$ & $\begin{array}{l}\text { The plan (Auckland Transport 2010), on page 4, states that Policy } \\
\text { 4.2.2 aims to make provisions for new modal interchanges. It is rec- } \\
\text { ommended that policy makers provide physical connections such } \\
\text { as sheltered walkways between stations/stops at transfer locations } \\
\text { to increase user comfort during transfer walking times. }\end{array}$ \\
\hline $\begin{array}{l}\text { Information } \\
\text { integration }\end{array}$ & $\begin{array}{l}\text { Partially } \\
\text { achieved }\end{array}$ & $\begin{array}{l}\text { The plan (Auckland Transport 2010), Objective 8.2 on page 27, } \\
\text { states plans to provide users with timetables at terminals and } \\
\text { stops, a journey planner website, customer self-service options, call } \\
\text { centers, and real-time displays at all RTN and QTN stations. A study } \\
\text { by Grotenhuis et al. (2007) showed that users desire en route (real- } \\
\text { time) information when making transfers, particularly non-frequent } \\
\text { PT users. Therefore, it is recommended that policy makers offer } \\
\text { transit users with an integrated information system that provides } \\
\text { real-time guidance en route (from start to end of trip) for travel } \\
\text { support. This can be a self-service option. }\end{array}$ \\
\hline
\end{tabular}

\section{Guideline B: Existing Transfer Routes}

To improve existing transfers, PT operators need to assess the existing facilities and change any possible attributes to make the connections more closely aligned to being planned. Use of this guideline is demonstrated with an example by providing recommendations for transfers at Britomart and Northern Busway, as shown in Table 5. 
Table 5. Recommendation to Make Transfers More Planned

\begin{tabular}{|c|c|}
\hline Britomart & Northern Busway \\
\hline $\begin{array}{l}\text { Network integration \& integrated timed-transfer: It is } \\
\text { recommended that further network integration is required at } \\
\text { Britomart to provide users with more flexibility in reaching their } \\
\text { desired destinations using PT. Operators should aim to minimize } \\
\text { the transfer waiting times by synchronizing scheduled routes. }\end{array}$ & \multirow{3}{*}{$\begin{array}{l}\text { Fare and ticketing integra- } \\
\text { tion: Findings suggest that } \\
\text { further integration among } \\
\text { operators is required to } \\
\text { make transfers of no extra } \\
\text { cost to the user (Sharaby } \\
\text { and Shiftan 2012). This } \\
\text { provision should be incor- } \\
\text { porated into the normal } \\
\text { ticketing system instead of } \\
\text { requiring transit users to } \\
\text { purchase separate tickets } \\
\text { such as the Northern Pass } \\
\text { to use transfer routes. }\end{array}$} \\
\hline $\begin{array}{l}\text { Information integration: Site observation revealed that transit } \\
\text { users making transfers at Britomart were often unclear about } \\
\text { how to make the connection. This finding indicates that more } \\
\text { information on connections, such as better signage, is required to } \\
\text { improve transit users' ease of making transfers. }\end{array}$ & \\
\hline $\begin{array}{l}\text { Integrated physical connection of transfers: More sheltered } \\
\text { waiting and walking areas should be provided for the bus service } \\
\text { to improve the level of comfort for users making transfers. }\end{array}$ & \\
\hline
\end{tabular}

\section{Conclusion}

The objective of this study was to provide policy makers and PT network planners with a more in-depth understanding of (1) the attributes that create "seamless" transfers in a multimodal public transport network and (2) transit users' perceptions of planned/unplanned transfers and, thus, their decision to use transfer routes. The following five attributes have been proposed to define planned transfers: network integration, integrated timed-transfer, integrated physical connection of transfers, information integration, and fare and ticketing integration.

Results of the analysis support the definition of planned transfer developed. Findings suggested that transit users have a higher willingness to use transfer routes when the connections are closely aligned to being planned. A theoretical general guideline has been developed to assist policy makers in designing "seamless" connections for new and existing transfer routes.

\section{References}

Atkins, S. T. 1990. Personal security as a transport issue: A state-of-the-art review. Transportation Reviews, 10(2): 111-125.

Auckland Transport 2010. Auckland Regional Public Transport Plan 2010: 1-140.

Auckland Transport. 2012. Britomart Transport Centre. Retrieved June 28, 2012, from http://www.britomart.co.nz. 
Bachok, S. 2007. What do passengers need out of public transport information systems? 29th Conference of Australian Institute of Transport Research, Adelaide, Australia.

Bamberg, S., M. Hunecke and A. Blobaum. 2007. Social context, personal norms and the use of public transportation: Two field studies. Journal of Environmental Psychology, 273: 190-203

Becker, A. J., and F. Spielberg. 1999. Implementation of a timed transfer network at Norfolk, Virginia. Transportation Research Record 1666: 3-13.

Beirao, G., and J. A. Sarsfield-Cabral. 2007. Understanding attitudes towards public transport and private car: A qualitative study. Transport Policy, 14(6): 478-489.

Blythe, P. T. 2004. Improving public transport ticketing through smart cards. Proceedings of the Institute of Civil Engineers: Municipal Engineer 157(ME I): 47-54.

Buehler, R. 2011. Determinants of transport mode choice: A comparison of Germany and the USA. Journal of Transport Geography, 19: 644-657.

Callaghan, L., and W. Vincent. 2007. Preliminary evaluation of Metro Orange Line Bus Rapid Transit Project. Transportation Research Record 2034: 37-44.

Carrus, G., P. Passafaro, and M. Bonnes. 2008. Emotions, habits and rational choices in ecological behaviours: The case of recycling and use of public transportation. Journal of Environmental Psychology, 28(1): 51-62.

Ceder, A. 2007. Public Transit Planning and Operation: Theory, Modelling and Practice. Oxford, UK, Elsevier.

Ceder, A., L.-A. Yann, and C. Coriat 2009. Measuring public transport connectivity performance applied in Auckland. Transport Research Record 2111: 139-147.

Clever, R. 1997. Integrated timed transfer. Transportation Research Record 1571: 109-115.

Currie, G., and C. Loader. 2010. Bus network planning for transfers and the network effect in Melbourne, Australia. Transportation Research Record 2145: 8-17.

Currie, G., and D. Willis. 1998. Melbourne bus rail interchange strategy. 22nd Australasian Transport Research Forum, Sydney, Australia.

Eboli, L., and G. Mazzulla. 2012. Performance indicators for an objective measure of public transport service quality. European Transport, 51, 1-21. 
Garcia, M. M., and S. Azan. 2005. Integrated transport systems in Latin America. Public Transport International, 54(5): 36-38.

Gatersleben, B., and D. Uzzell. 2007. Affective appraisals of the daily commute. Environment and Behaviour, 39(3): 416-431.

Graybill, F. A. 1976. Theory and Application of the Linear Model. North Scituate, USA, Duxbury Press.

Grotenhuis, J. W., B. W. Wiegmans, and P. Rietveld, 2007. The desired quality of integrated mulitmodal travel information in public transport: Customer needs for time and effort savings. Transport Policy, 14: 27-38.

Guo, Z., and N. H. M. Wilson. 2004. Assessment of the transfer penalty for transit trip. Transportation Research Record 1872: 10-18.

Guo, Z., and N. H. M. Wilson. 2007. Modeling the effect of transit system transfer on travel behaviour. Transportation Research Record 2006: 11-20.

Guo, Z., and N. H. M. Wilson. 2011. Assessing the cost of transfer inconvenience in public transport systems: A case study of the London Underground. Transporation Research Part, 45: 91-104.

Hadas, Y., and P. Ranjitkar. 2012. Modeling public-transit connectivity with spatial quality-of-transfer measurements. Journal of Transport Geography, 22: 137-147.

Heath, Y., and R. Gifford. 2002. Extending the theory of planned behaviour: Predicting the use of public transportation. Journal of Applied Social Psychology, 32(10): 2154-2189.

Hidalgo, D. 2009. Citywide transit integration in a large city: The Interligado system of Sao Paulo, Brazil. Transportation Research Record 2114: 19-27.

Hutchinson, T. D. 2009. The customer experience when using public transport: $A$ review. Instiution of Civil Engineers: Municipal Engineer, 162(ME3): 149-157.

Ibrahim, M. F. 2003. Improvements and integration of a public transport system: The case of Singapore. Cities, 20(3): 205-216.

Iseki, H., and B. D. Taylor. 2009. Not all transfers are created equal: Towards a framework relating transfer connectivity to travel behaviour. Transport Reviews, 29(6): 777-800. 
Kumar, P., S. Y. Kulkarni, and M. Parida. 2011. Security perceptions of Delhi commuters at Metro-bus interchange in multi modal perspective. Journal of Transport Security 4: 295-307.

Liu, R., R. M. Pendyala, and S. Polzin. 1997. Assessment of intermodal transfer penalties using stated preference data. Transportation Research Record 1607: 74-80.

Luk, J., and P. Olszewski. 2003. Integrated public transport in Singapore and Hong Kong. Road and Transport Research, 12(4): 41-51.

Matas, A. 2004. Demand and revenue implications of an integrated public transport policy: The case of Madrid. Transport Reviews, 24(2): 195-217.

Maxwell, R. R. 1999. Intercity rail fixed-interval, timed-transfer, multihub system: Applicability of the Integraler Taktfahrplan Strategy to North America. Transportation Research Record 1691: 1-11.

Maxwell, R. R. 2003. Converting a large region to a multimodal pulsed-hub public transport network. Transportation Research Record 1835: 128-136.

May, T. 2011. Social Research: Issues, Methods and Process. Maidenhead, England, McGraw-Hill Education.

Molin, E., and C. Chorus. 2009. The need for advanced public trasnport information services when making transfers. European Journal of Transport and Infrastructure Research EJTIR, 4(9): 397-410.

Muller, T., and P. Furth. 2009. Transfer scheduling and control to reduce passenger waiting time. Transport Research Record 2112: 111-118.

Sharaby, N., and Y. Shiftan. 2012. The impact of fare integration on travel behavior and transit ridership. Transport Policy, 21: 63-70.

Statistics New Zealand. 2012. New Zealand General Social Survey Retrieved June 29, 2012, from: http://www.stats.govt.nz/browse_for_stats/people_and_communities/Households/nzgss_HOTP2010/Definitions.aspx.

Ulengin, F., S. Onsel, Y. I. Topcu, E. Aktas, and O. Kabak 2007. An integrated transportation decision support system for transportation policy decisions: The case of Turkey. Transporation Research Part A, 41: 80-97.

Vande Walle, S., and T. Steenberghen. 2006. Space and time related determinants of public transport use in trip chains. Transporation Research Part A, 40: 151-162. 
Vassallo, J. M., F. Di Ciommo, and A. Garcia. 2012. Intermodal exchange stations in the city of Madrid. Transportation 39: 975-995.

Verma, A., and S. L. Dhingra. 2005. Feeder bus routes generation within integrated mass transit planning framework. Journal of Transportation Engineering, 131(11): 822-834.

Volinski, J., and O. Page. 2006. Developing bus transfer facilities for maximum transit agency and community benefit. Transportation Research Record 1955: 3-7.

Wang, G., E. D. Goodman, and W. F. Punch. 1997. Toward the optimization of a class of black box optimization algorithms. IEEE International Conference on Tools with Artificial Intelligence.

Xumei, C., L. Qiaoxian, and D. Guang. 2011. Estimation of travel time values for urban public transport passengers based on SP survey. Journal of Transportation Systems Engineering and Information Technology, 11(4): 77-84.

Zhang, L., J. Li, K. Zhou, S. Gupta, M. Li, W. Zhang, M. A. Miller, and J. A. Misener. 2011. Traveler information tool with integrated real-time transit information and multimodal trip planning. Transportation Research Record 2215: 1-10.

Zhou, X., X. Yang, and Y. Lao (2007). Public transport service level influence on travel mode choice. International Conference on Transportation Engineering, Chengdu, China.

Zografos, K., V. Spitadakis, and K. Androutsopoulos. 2008. Integrated passenger information system for multimodal trip planning. Transportation Research Record 2072: 20-29.

\section{About the Authors}

Avishai (Avi) Ceder (a.ceder@auckland.ac.nz) is Professor and Chair in Transportation in the Department of Civil and Environmental Engineering at the University of Auckland (UoA) and Director of the Transportation Research Centre (TRC) at UoA. He was Head of the Transportation Engineering and Geo-Information Department at the Technion and a Visiting Professor at the Massachusetts Institute of Technology, the University of California at Berkeley, and others. In 2007, he published the book Public Transit Planning and Operation: Theory, Modeling and Practice (Elsevier, Oxford, UK), which was translated into Chinese by the Tsinghua publishing house, Beijing, China, in June 2010. 
SUbeh CHOWdhURY graduated with a Bachelor of Engineering (Civil and Environmental) from the University of Auckland. She has worked with two international engineering consultancies in New Zealand and is currently a doctoral student at the University of Auckland. She presented at the TRB 2012 annual conference. 